\title{
CONSUMER CULTURE THEORY (CCT) JÁ É UMA ESCOLA DE PENSAMENTO EM MARKETING?
}

\author{
CONSUMER CULTURE THEORY (CCT) - IS THERE ALREADY A SCHOOL OF THOUGHT IN \\ THE AREA OF MARKETING?
}

¿CONSUMER CULTURE THEORY (CCT) YA ES UNA ESCUELA DE PENSAMIENTO EN MARKETING?

\section{RESUMO}

A década de 1980 trouxe uma visão alternativa à corrente positivista predominante no campo de pesquisa do consumidor: a Consumer Culture Theory (CCT), que assume uma orientação epistemológica baseada no interpretativismo e na pesquisa qualitativa. Diante do destaque alcançado pela CCT, levantou-se a seguinte questão: a CCT já pode ser considerada uma escola de pensamento em marketing autônoma? Pautados em três critérios fundamentais para a qualificação de uma escola de pensamento (reconhecimento acadêmico, corpo de conhecimento e contribuições), foi realizada uma desk research, baseada em periódicos e artigos da área e na construção de um corpus de pesquisa construído com base nas referências contidas no texto seminal Consumer Culture Theory (CCT): twenty years of research. A conclusão é de que a CCT atende aos critérios adotados na presente pesquisa, podendo ser considerada uma escola de pensamento a utônoma dentro do campo de pesquisa do consumo.

PALAVRAS-CHAVE Consumer Culture Theory, escola de pensamento, interpretativismo, pesquisa de consumo, desk research

Brunno Fernandes da Silva Gaião brunno_gaiao@hotmail.com

Mestre pelo Programa de Pós-Graduação em Administração, Universidade Federal de Pernambuco - Recife - PE, Brasil

Ildembergue Leite de Souza ildembergue.leite@gmail.com

Mestre pelo Programa de Pós-Graduação em Administração, Universidade Federal de Pernambuco - Recife - PE, Brasil

André Luiz M. de Souza Leão andre.leao@pq.cnpq.br

Professor do Programa de Pós-Graduação em Administração, Universidade Federal de Pernambuco - Recife - PE, Brasil

\begin{abstract}
The 1980s brought an alternative view to the positivist predominant current in consumer research field: Consumer Culture Theory (CCT), which assumes an epistemological orientation based on interpretivism and qualitative research. Given the prominence achieved by CCT it's raised the follow question: Consumer Culture Theory can be considered an autonomous marketing school of thought? Guided by three fundamental criteria for qualifying a school of thought (academic recognition, body of knowledge and contributions), a desk research was conducted, based on journals and papers in the field and in a research corpus built from the references included in the seminal text Consumer Culture Theory (CCT): Twenty Years of Research. Conclusion is that CCT meets the criteria adopted in this research and, thus, can be considered an autonomous marketing school of thought within the field of consumer research.

Keywords Consumer Culture Theory, school of thought, interpretivism, consumer research, desk research.

Resumen La década de 1980 trajo una visión alternativa a la corriente positivista predominante en el campo de investigación del consumidor: la Consumer Culture Theory (CCT), que asume una orientación epistemológica basada en el interpretativismo y en la investigación cualitativa. Frente a la relevancia alcanzada por la CCT, se planteó la siguiente cuestión: ¿La CCT ya puede ser considerada una escuela autónoma de pensamiento en marketing? Pautados en tres criterios fundamentales para la calificación de una escuela de pensamiento (reconocimiento académico, cuerpo de conocimiento y contribuciones), fue realizada una desk research, basada en periódicos y artículos del área y en la construcción de un corpus de investigación construido con base en las referencias contenidas en el texto seminal Consumer Culture Theory (CCT): twenty years of research. La conclusión es que la CCT atiende a los criterios adoptados en la presente investigación, pudiendo ser considerada una escuela autónoma de pensamiento dentro del campo de investigación del consumo. Palabras clave Consumer Culture Theory, escuela de pensamiento, interpretativismo, investigación de consumo, desk research.
\end{abstract}




\section{INTRODUÇÃO}

O estudo do comportamento do consumidor surgiu e formalizou-se dentro da área de marketing somente nas últimas cinco décadas, período em que se passou a estudar as práticas dos indivíduos envolvidos nos processos de seleção, aquisição, uso e descarte de produtos ou serviços (KASSARJIAN e GOODSTEIN, 2010).

Em seu primeiro momento, na década de 1950, o interesse pelo entendimento das ações do consumidor surgiu da percepção de alguns economistas de que a influência das expectativas e atitudes dos consumidores sobre a dinâmica do mercado não era levada em conta em seus estudos. Mas somente em meados dos anos 1960 é que foram criadas, de fato, as bases fundadoras que vieram a consolidar o estudo do comportamento do consumidor, por meio de estudos de cunho behaviorista. Na década seguinte, os estudos cognitivistas acerca do processamento de informação e da escolha por parte do consumidor ganharam destaque, sendo, então, incorporados à área de estudo (KASSARJIAN e GOODSTEIN, 2010).

Na década de 1980, entretanto, outra corrente paradigmática apresenta-se como alternativa à epistemologia positivista dominante: o interpretativismo. Apesar de a aplicação de estudos interpretativistas ao consumo ter seus primórdios apontados ainda nos anos 1930 (TADAJEWSKI, 2006), essa abordagem ganhou força, nas últimas três décadas, dentro dos estudos relacionados ao consumo. Fortemente influenciada pela antropologia cultural, tal perspectiva leva em conta a complexidade da realidade sociocultural, dedicando especial atenção para a subjetividade da natureza humana e para a importância que têm os aspectos simbólicos dentro das interações sociais. Sendo assim, como objetivo primeiro dessa corrente de pensamento, está o entendimento aprofundado dos fenômenos de consumo e seus significados, questões essas até então pouco ou nada consideradas pelo positivismo (BELK, 1986; HOLBROOK E O'SHAUGHNESSY, 1988; KASSARJIAN e GOODSTEIN, 2010).

Batizado por Arnould e Thompson (2005) com o nome de Consumer Culture Theory (CCT), um conjunto de perspectivas teóricas tem guiado o movimento alternativo ao estudo do comportamento do consumidor. Esses estudos, que privilegiam a metodologia de pesquisa qualitativa, têm se dedicado à compreensão do consumo, das escolhas comportamentais e das práticas sociais, todos enxergados como um fenômeno cultural, uma oposição, portanto, à visão predo- minantemente psicológica ou econômica adotada na academia até então.

Nos últimos vinte e cinco anos, a influência da CCT sobre os estudos do consumo cresceu de tal maneira que hoje já é possível perceber claramente um destacado espaço ocupado por pesquisas dessa corrente no cenário acadêmico internacional. Apesar de ainda ser tratada como alternativa, os fundamentos teóricos dessa perspectiva têm sido cada vez mais adotados entre os pesquisadores de marketing, quadro esse que motiva perguntar se a CCT já pode ser considerada uma escola de pensamento independente da escola do Comportamento do Consumidor ou se ainda representa apenas uma área temática de pesquisa subjacente a essa última.

De modo análogo, recentemente, tal questão foi levantada acerca do marketing de relacionamento, tendo levado Palmer, Lindgreen e Vanhamme (2005) a sugerir a existência de três escolas de pensamento nessa área, já definida anteriormente de maneira mais ampla como paradigma alternativo à abordagem transacional de marketing (SHETH e PARVATIYAR, 1995).

É importante reforçar o fato de que o objetivo deste artigo não é revisar o trabalho realizado por Arnould e Thompson, muito menos traçar um perfil da CCT. A proposta aqui é discutir se essa "nova" corrente de estudos já apresenta consistência e envergadura suficientes para ser considerada uma nova escola de pensamento em marketing. Para tanto, a presente pesquisa está pautada em critérios discutidos na literatura acerca do que constitui uma escola de pensamento.

No processo de análise da CCT como uma escola de pensamento, este estudo revelará, também, aspectos outros relacionados aos trabalhos alinhados com esta perspectiva de pesquisa, tais como o quantitativo das temáticas abordadas, os aportes teóricos utilizados e os métodos de pesquisa empregados, bem como os espaços existentes na academia para a discussão de problemas e estudos na área da CCT.

\section{CONSUMER CULTURE THEORY}

Nas últimas décadas, foi possível assistir ao movimento de declínio da sociedade pautada na produção e de ascensão de um mundo social contemporâneo que tem na esfera do consumo sua força motriz. O hedonismo, a fragmentação dos indivíduos e as crises de identidade são algumas características desta que vem sendo denominada como "pós-modernidade". Na rea- 
lidade da cultura de consumo do mundo moderno, as relações sociais, valores culturais, ideias e identidades básicas são guiados pela ética do consumo e não mais da produção (FEATHERSTONE, 1995; SLATER, 2002).

De acordo com Baudrillard (2007), a sociedade de consumo trata os objetos como objetos-símbolos, que são consumidos por seu valor simbólico e não pelo utilitário. Os bens não são mais valorados economicamente, mas, sim, simbólica e culturalmente. Nesse cenário, os signos e imagens desenvolvem uma relação explícita com a cultura do consumo (SLATER, 2002). Os bens de consumo passam a ser entendidos como a parte visível da cultura, permitindo aos indivíduos envolver-se significativamente com os outros consumidores e com a sociedade (DOUGLAS e ISHERWOOD, 2009).

$\mathrm{Na}$ esteira dessa mudança, parte das pesquisas relacionadas ao consumo e ao consumidor se voltou para aspectos socioculturais do fenômeno do consumo, alcançando cada vez mais destaque no âmbito acadêmico. Um número crescente de estudiosos passou a interessar-se por questões pouco abordadas até então. E, em 2005, baseados nos trabalhos publicados no Journal of Consumer Research, Erci Arnould e Craig Thompson desenvolveram um estudo caracterizando aquela que seria uma nova corrente de pesquisa, denominada por eles mesmos como Consumer Culture Theory - CCT (PINTO e LARA, 2009).

A CCT debruça-se sobre a maneira como os consumidores geram e modificam continuamente os significados simbólicos de seu consumo, presentes em marcas, propagandas e no próprio uso dos bens materiais como um todo, construindo expressões de suas particularidades pessoais e sociais. São exploradas questões como a relação entre contextos culturais e sociais, os modos de interação entre consumidores e empresas e a construção, alteração e distribuição dos significados do consumo (ARNOULD e THOMPSON, 2007).

Os trabalhos dessa nova corrente buscam, por meio de situações particulares de consumo, desenvolver o conhecimento acerca do fenômeno do consumo em seus mais diversos aspectos. Nesse processo, percebe-se a prevalência de estudos identificados como qualitativos, em detrimento de pesquisas que utilizem surveys ou experimentos, o que ocorre devido à disposição para acessar questões marcadamente subjetivas. Contudo, é preciso destacar que, mesmo com a predominância de estudos qualitativos, a CCT não defende a predileção por métodos qualitativos ou quantitativos em suas pesquisas (ARNOULD e THOMPSON, 2005).

É válido ressaltar, ainda, que o artigo desenvolvido por Arnould e Thompson (2005), no qual é apresentada a CCT, baseia-se em artigos publicados exclusivamente no Journal of Consumer Research. Moisander, Peñaloza e Valtonen (2009) destacam a necessidade de ampliação da perspectiva de Arnould e Thompson, voltando-se particularmente para a produção europeia. De fato, uma vez que autores como Pierre Bourdieu, Jean Baudrillard, Michel Foucault e Karl Marx influenciaram sobremaneira os alicerces da CCT, não se deve desconsiderar os trabalhos europeus que são desenvolvidos na área atualmente. Contudo, esse argumento, que poderia ser interpretado negativamente em relação à consolidação da CCT, corrobora a afirmação de que a CCT é representativa de um movimento mais amplo, do qual fazem parte pesquisadores presentes em diferentes áreas do globo.

Conscientes de que a CCT não se encontra unifica$\mathrm{da}$, mas de que se assemelha a uma família de interesses e perspectivas teóricas que compartilham uma mesma orientação de pesquisa, Arnould e Thompson definiram quatro grandes temáticas que pautam os estudos nessa área, apresentadas no framework a seguir, publicado em 2007 (Figura 1).

Os consumidores são vistos como produtores de cultura, em contraste com a tradicional visão antropológica de pessoas como portadores de cultura. Os consumidores constroem mundos culturais distintivos, fragmentários, autosselecionados e, às vezes, transitórios, e criam sentimentos de solidariedade social, por meio da busca de interesses comuns de consumo. Como forma de reação a essas situações potencialmente alienantes e isolantes, os consumidores forjam identificações coletivas efêmeras e constroem rituais de solidariedade que são pautados em interesses de estilo de vida e ocupações de lazer comuns. As "culturas de mercado" definem suas fronteiras simbólicas por meio de uma oposição contínua às normas do estilo de vida dominante (SCHOUTEN e MCALEXANDER, 1995; MUNIZ e O'GUINN, 2001; COVA, PACE, PARK, 2007; OUWERSLOOT E ODEKERKEN-SCHRÖDER, 2008).

Em seguida, a CCT aborda as estruturas institucionais e sociais que influenciam o consumo de maneira sistemática. Estudiosos investigam como os comportamentos dos consumidores e suas escolhas de consumo são moldados por hierarquias de gênero, classe social, família, etnia, domicílios e outros grupos formais (ARNOULD e THOMPSON, 2005, 2007). Valendo-se dos "padrões sócio-históricos de consumo", a CCT questiona as relações entre as experiências dos consumidores, os sistemas de crenças, práticas e essas estruturas de base institucional 
e social (HOLBROOK, 1993; HOLT, 1997; CROCKETT, 2008; HAMLETT, 2008; DOLAN, 2009; DWYER, 2009).

Em relação ao "projeto de identidade dos consumidores", a CCT debruça-se sobre as formas pelas quais os indivíduos, utilizando os bens de consumo disponíveis no mercado, forjam um sentido diversificado e, muitas vezes, um senso fragmentado do "eu". Nesse sentido, o mercado torna-se uma fonte de recursos míticos e simbólicos por meio dos quais os indivíduos, incluindo aqueles que carecem de para participar do mercado como consumidores de direito pleno, elaboram narrativas de identidade (ARNOULD e THOMPSON, 2005, 2007). Pesquisadores têm se voltado para questões ligadas à maneira como os consumidores assumem posições de consumo oferecidas pelo mercado e à relação dessas com os projetos de identidade dos consumidores (BELK, 1988; HOLIDAY e CAIRNIE, 2007; HEARN, 2008; THERKELSEN e GRAM, 2008).

Finalmente, o quarto grupo temático investiga a ideologia do consumidor - sistemas de significados que canalizam e reproduzem ações e pensamentos dos consumidores de tal forma a defender os interesses dominantes na sociedade. Examina as influências que a globalização cultural e econômica exerce sobre projetos de identidade do consumidor e sobre os padrões que definem a identidade de interação social em contextos sociais distintos (TRENTMANN, 2009). São investigadas, ainda, as formas como alguns sistemas de produção cultural, como as comunicações de marketing ou a indústria da moda, sistematicamente levam os consumidores em direção a determinados tipos de projetos de identidade (HIRSCHMAN e THOMPSON, 1997; PEÑALOZA e GILLY, 1999; BOTTERILL, 2007; WISSINGER, 2009).

\section{PROCEDIMENTOS METODOLÓGICOS}

A avaliação adotada para responder à questão de pesquisa foi baseada em três critérios fundamentais, propostos e confirmados na literatura voltada para a

\section{Figura 1 - Framework sintético da CCT}

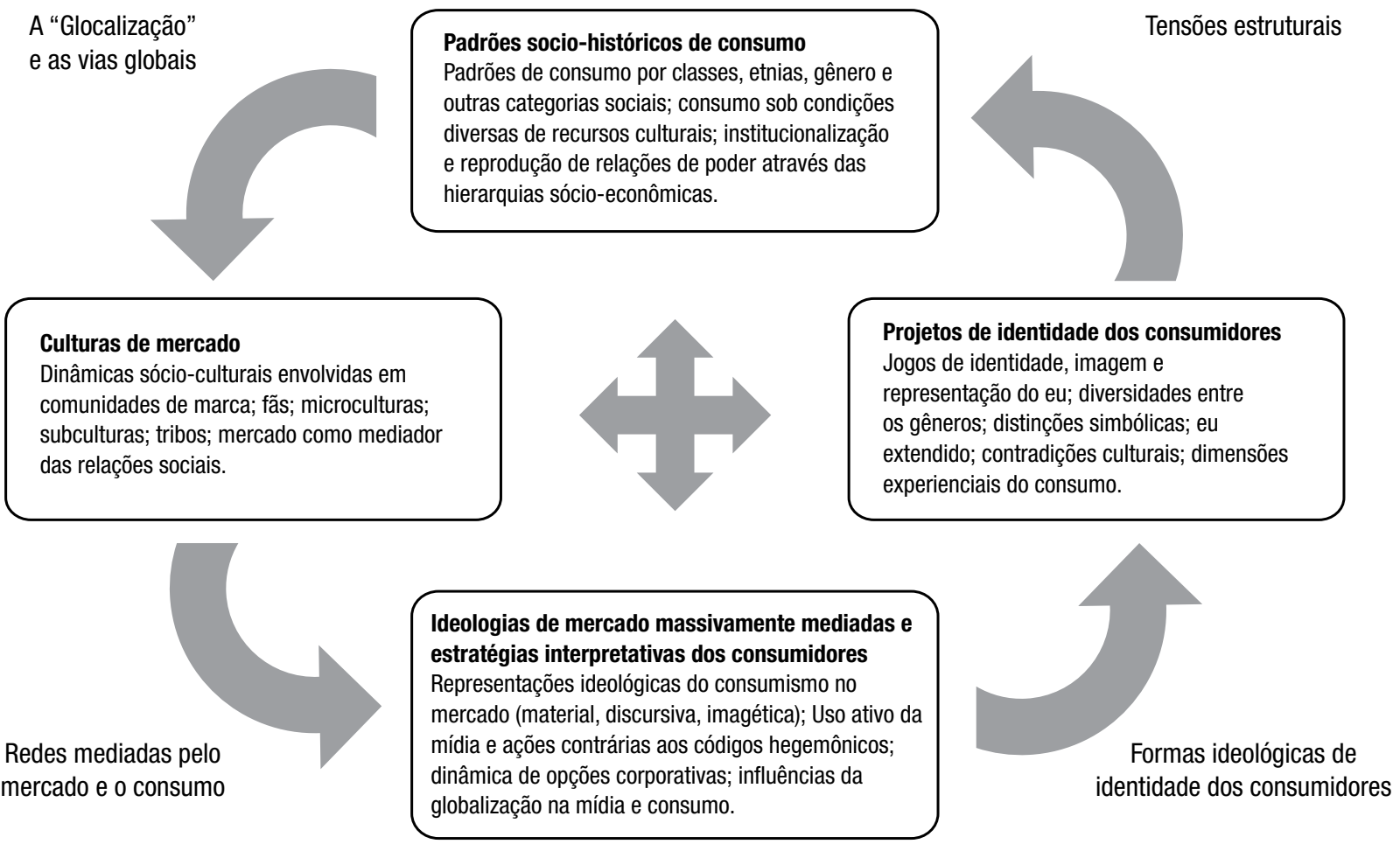


filosofia da ciência. Uma escola de pensamento em marketing, de acordo com Shaw, Jones e McLean (2010, p. 28), é definida por três critérios:

Primeiro, uma escola representa um corpo substancial de conhecimento. Segundo, uma escola é desenvolvida por vários estudiosos. Terceiro, uma escola descreve ou explica pelo menos um aspecto sobre o que, como, quem, por que, quando e onde se dão as atividades de marketing.

Tais critérios são ratificados pela proposta de Sheth, Gardner e Garret (1988), segundo a qual uma escola de pensamento deve atender a três critérios: primeiro, desenvolver um foco distinto e de relevância para os objetivos do marketing, definindo, inclusive, quais os beneficiários dessas práticas do marketing; segundo, deve apontar por que as atividades são ou devem ser realizadas por aqueles envolvidos no processo; e, finalmente, uma escola de pensamento deve estar representada por um número significante de estudiosos por meio das contribuições dadas por esses para a construção do pensamento.

As duas proposições guardam semelhanças; contudo, para efeito da presente pesquisa, os critérios enumerados por Shaw, Jones e McLean (2010) mostraram-se mais pertinentes, por conta da precisão de sua proposta. Dessa forma, serão adotados três critérios para a avaliação da CCT como uma escola de pensamento.

O primeiro critério, aqui tratado como "reconhecimento acadêmico", foi verificado com base em: a) a existência de publicações relacionadas à CCT em periódicos de renome internacional na área de marketing; b) o lançamento de periódicos acadêmicos voltados especificamente para estudos sobre cultura de consumo, confirmando a relevância do tema; e, finalmente, c) a presença significativa de estudiosos alinhados com as perspectivas da CCT e a existência, entre estes, de nomes de reconhecida projeção no meio científico internacional.

O segundo critério, referente ao "corpo de conhecimento", foi avaliado sob três aspectos. Primeiro, se havia no artigo em análise a abordagem de um ou mais campos temáticos propostos por Arnould e Thompson (2005), que, como visto em seção anterior, tratam de (1) projetos de identidade do consumidor, (2) culturas de mercado, (3) padrões sócio-históricos do consumo e (4) ideologias de mercado massivamente mediadas e estratégias interpretativas dos consumidores. Os segundo e terceiro aspectos detiveram-se à identificação e análise da pertinência das abordagens escolhidas em relação ao aporte teórico e aos métodos adotados.

Por fim, as "contribuições" trazidas pela CCT completam os requisitos exigidos a uma escola de pensamento. Tais contribuições dão-se pelas respostas às perguntas quê, como, quem, por quê, quando e onde, importantes para o entendimento das atividades de marketing. Tais aspectos estão associados a boas perguntas que se mostram fundamentais para se definir o problema de pesquisa, porque implicam o que o pesquisador e seus leitores não sabem ou não entendem, mas deveriam (BOOTH, COLOMB, WILLIAMS, 2008).

Os três critérios supracitados, que serviram de guia para a análise do presente estudo, estão resumidos no Quadro 1.

Para proceder a essa avaliação, foi adotado o método desk research ou pesquisa de dados secundários, de caráter exploratório-descritivo (PIETRANGELO, 2006), que se demonstrou o mais adequado para a consecução dos resultados.

Para o primeiro critério - "reconhecimento acadêmico" - foi realizada uma primeira etapa da desk research, na qual se buscou identificar periódicos dedicados es-

\section{Quadro 1 - Critérios para a constituição de uma escola de pensamento}

\begin{tabular}{|l|l|}
\hline \multicolumn{1}{|c|}{ Critérios } & \multicolumn{1}{c|}{ Definição } \\
\hline Reconhecimento acadêmico & $\begin{array}{l}\text { Adesão de número significante de estudiosos alinhados com princípios da CCT, incluindo, entre esses, } \\
\text { nomes importantes no cenário acadêmico; existência de publicações relacionadas com a CCT em } \\
\text { periódicos de renome; existência de periódicos científicos específicos para publicação de estudos } \\
\text { sobre o tema. }\end{array}$ \\
\hline Corpo de conhecimento & $\begin{array}{l}\text { Produção de conhecimento por meio de escolhas relativas ao campo de estudo, escolhas teóricas e } \\
\text { metodológicas coerentes à abordagem da CCT. }\end{array}$ \\
\hline Contribuições & $\begin{array}{l}\text { Resposta a uma ou mais questões referentes às atividades do marketing (o quê, como, quem, quando, } \\
\text { onde). }\end{array}$
\end{tabular}


pecificamente a essa área, bem como a ocorrência de artigos alinhados à CCT em periódicos de abordagens distintas. Com base nesses periódicos, considerou-se a adesão significativa de estudiosos, bem como a projeção acadêmica dos autores engajados à CCT.

Para o segundo e terceiro critérios, construiu-se um corpus de pesquisa (BAUER e AARTS, 2005) determinado com base nas referências bibliográficas contidas no texto seminal Consumer Culture Theory (CCT): twenty years of research, de autoria de Arnould e Thompson (2005). A escolha de tal delimitação justifica-se pela importância do referido trabalho para a edificação de uma corrente de estudos voltada para a valorização de aspectos socioculturais, simbólicos e ideológicos relacionados ao consumo.

Com o cenário de pesquisa delimitado, todas as referências, num total de 166, foram pesquisadas, pelo título e autor, na plataforma EBSCO. Feita a busca, verificou-se a indisponibilidade de 26 publicações, resultando em um corpus inicial de 140 artigos. A etapa seguinte coincidiu com a depuração do primeiro aspecto de análise do segundo critério adotado, os "campos temáticos" da CCT. A classificação foi feita com base na leitura de todos os artigos, eliminando-se aqueles que tratavam de questões não alinhadas a estes. A filtragem resultou num conjunto de 80 artigos, tratados aqui como o corpus final da pesquisa (Tabela 1).

\begin{tabular}{|c|c|}
\hline $\begin{array}{c}\text { Tabela } 1 \text { - Construção do corpus de } \\
\text { pesquisa com artigos sobre CCT }\end{array}$ \\
\hline Corpus & $\mathbf{N}^{0}$ de artigos \\
\hline Inicial & 166 \\
\hline Disponível & 140 \\
\hline Seleção final & 80 \\
\hline
\end{tabular}

Pela própria natureza do primeiro critério considerado (reconhecimento acadêmico), este foi explorado de maneira descritiva, uma vez que se referiu a um mapeamento do alcance do campo de pesquisa. Também de modo primordialmente descritivo, foi tratado o primeiro aspecto do segundo critério (campos temáticos da CCT), que foi inferido no próprio processo de depuração do corpus de pesquisa, logo se referindo fortemente a um processo classificatório do que se podia ou não considerar como CCT. Apesar disso, na medida em que os resultados acerca dos campos utilizados são apresentados, um exercício de análise crítica foi feito, ao se refletir sobre os campos mais adotados nos trabalhos que compuseram o corpus. Essa postura crítica tornou-se procedimento analítico nos demais aspectos do segundo critério (aporte teórico e métodos adotados), bem como do terceiro critério (contribuições). Além de serem apresentados descritivamente, tais aspectos passaram por um escrutínio crítico. Na medida em que os artigos foram analisados em relação aos critérios desses três pontos, também foram identificadas potenciais inconsistências.

\section{RESULTADOS}

A seguir, serão apresentados os resultados da análise de cada um dos critérios adotados na avaliação da CCT como uma escola de pensamento, de acordo com o descrito na seção anterior.

\section{Reconhecimento acadêmico}

Como referência para a identificação de periódicos renomados na área, utilizou-se como critério a lista das publicações com reconhecida importância na difusão do conhecimento acadêmico de marketing, disponibilizada pela Academy of Marketing Science (2010). Entre os periódicos ali indicados como os 10 primeiros, foram identificados artigos relacionados à abordagem da CCT nos seguintes periódicos: Journal of Marketing, Journal of Marketing Research, Journal of Retailing, Journal of the Academy of Marketing e Journal of Advertising. Eles são, respectivamente, primeiro, terceiro, quarto, quinto e nono colocados na lista consultada. Além destes, o Journal of International Marketing e o Journal of American Culture apresentam publicações frequentes relacionadas com temáticas e abordagens pertinentes à CCT, tendo havido uma edição especial do Journal of American Culture direcionada especificamente para a temática da cultura de consumo, em março de 2007.

A produção crescente de trabalhos voltados para a cultura de consumo demandou a criação de espaços destinados diretamente para a discussão de assuntos relacionados com essas temáticas. Em 1997, antes mesmo do surgimento do termo CCT, foi criada a revista Consumption, Markets and Culture. Anos depois, em 2001, uma nova revista específica para o tema foi lançada, o Journal of Consumer Culture. Além disto, desde 2006, acontece anualmente a Consumer Culture Theory Conference. O evento tem como proposta a criação de um 
espaço dedicado ao compartilhamento de ideias entre os pesquisadores da cultura de consumo espalhados por todo o mundo.

O resultado da aplicação do primeiro filtro na construção do corpus de pesquisa ratificou a adesão de um número expressivo de estudiosos dedicados a questões pertencentes ao universo de estudos da CCT. Como visto anteriormente, dos 140 artigos usados como referência no trabalho proposto por Arnould e Thompson (2005), 80 textos abordavam temas alinhados com a CCT, ou seja, um volume representativo que ultrapassa $57 \%$ do total.

Por fim, dezenas são os autores que têm publicado artigos relacionados ao campo da CCT nesses periódicos, com destaque para Alladi Venkatesh, Douglas B. Holt, Elizabeth C. Hirschman, Fuat Firat, Hope Schau, John F. Sherry, Ruby Dholakia e Russell W. Belk, entre outros com reconhecido valor acadêmico internacional na área de marketing.

\section{Corpo de conhecimento}

A avaliação do corpo de conhecimento, segundo critério de análise, tratou dos campos temáticos da CCT quanto à frequência com que foram abordados nos artigos estudados, considerando, também, se a presença desses campos se deu de maneira isolada ou combinada entre eles. Os métodos adotados e as teorias abordadas também foram avaliados pela distribuição que apresentaram entre os artigos do corpus de pesquisa, numa primeira instância, bem como foram escrutinados quanto à pertinência e aderência dessas escolhas em relação à abordagem da CCT.

\section{Campos temáticos da CCT}

Entre os 80 artigos do corpus final da pesquisa, o padrão sócio-histórico de consumo e os projetos de identidade do consumidor foram os campos temáticos da CCT com maior presença nos artigos. Vale destacar que, em muitos artigos, mais de uma temática foi abordada pelos autores e que cada um dos quatro campos temáticos, em pelo menos uma ocasião, foi analisado juntamente com uma das outras três temáticas. A distribuição de cada um dos campos temáticos pode ser acompanhada na Tabela 2.

A predominância de estudos voltados para as temáticas de padrões sócio-históricos de consumo e projetos de identidade do consumidor revela uma presença mais acentuada de questões voltadas para a influência das estruturas institucionais e sociais sobre o consumo e para a construção identitária dos consumidores.

A grande maioria dos artigos do corpus da pesquisa debruça-se sobre um único campo temático da CCT. No entanto, alguns artigos focam dois e até três campos temáticos, não havendo nenhum artigo que tenha tratado, ao mesmo tempo, dos quatro campos temáticos em seu conteúdo (vide Tabela 3).

Em relação aos artigos que trabalham com mais de um campo temático, os dados reforçam o que foi discutido anteriormente. A relação direta entre padrões sócio-históricos de consumo e projetos de identidade dos consumidores foi a mais recorrente no corpus. Essa relação debruça-se sobre tensões estruturais, voltadas para as questões de reprodução social e construção identitária dos indivíduos. Neste ponto, busca-se entender como indivíduos podem usar o consumo como meio para superar e alterar aspectos interiorizados pelo processo de socialização.

Em números absolutos, essas duas temáticas também se destacam. Padrões sócio-históricos de consumo e projetos de identidade dos consumidores são abordados, respectivamente, em 11 e 10 artigos dos 16 em questão. De certa forma, essas duas temáticas referem-se à relação da estrutura com o nível individual do consumo. O fato de estas aparecerem de

\section{Tabela 2 - Presença dos campos temáticos da CCT nos artigos selecionados}

\begin{tabular}{|c|c|c|}
\hline Campo temático & $\begin{array}{l}N^{0} \text { de artigos } \\
\text { dedicados ao tema }\end{array}$ & $\begin{array}{l}\% \text { de artigos } \\
\text { dedicados ao tema }\end{array}$ \\
\hline Padrão sócio-histórico de consumo & 32 & 40,00 \\
\hline Projetos de identidade do consumidor & 28 & 35,00 \\
\hline Culturas de mercado & 19 & 23,75 \\
\hline $\begin{array}{l}\text { Ideologias de mercado massivamente mediadas e estratégias interpretativas dos } \\
\text { consumidores }\end{array}$ & 19 & 23,75 \\
\hline
\end{tabular}


modo mais contundente parece evocar uma herança da perspectiva do comportamento do consumidor, propensa a olhar prioritariamente para o indivíduo. Apesar disso, esses campos, bem como os artigos ali identificados, realizam essa investigação de maneira alinhada à perspectiva culturalista em detrimento da cognitivista daquela escola, sugerindo que tal preferência seja demonstrativa de uma agenda de pesquisa consolidada no campo de pesquisa do consumidor de maneira mais ampla.

\section{Aporte teórico}

Diversos são os aportes teóricos utilizados nos artigos avaliados. Nesse sentido, buscou-se organizar conjuntos de teorias, construtos e perspectivas teóricas que demonstrassem aproximações acerca de sua finalidade. Nessa empreitada, foram identificados cinco grupos (Quadro 2).

Em relação aos temas da CCT, esses grupos de aporte teóricos foram identificados em um ou mais deles, apresentando, nesses casos, ênfases diferentes (a Figura 2 ilustra isso). Enquanto os grupos teóricos "representações do "eu" e "comunidades de consumo" são usados apenas em um tema da CCT cada, os grupos "distinções e estruturas sociais" e "ideologias e discursos de mercado" são utilizados primordialmente em um dos temas, mas com menor ênfase num segundo. O grupo teórico denominado "sistemas de produção cultural", por sua vez, também é utilizado primordialmente por um dos temas, mas é recorrente nos demais.

\section{Tabela 3 - Quantidade de campos temáticos da CCT abordados por artigo}

\begin{tabular}{|c|c|c|}
\hline Quantidade de campos temáticos abordados/artigo & $\mathbf{N}^{0}$ de artigos & $\%$ de artigos \\
\hline 1 & 64 & 80,00 \\
\hline 2 & 14 & 17,50 \\
\hline 3 & 2 & 2,50 \\
\hline 4 & 0 & 0,00 \\
\hline
\end{tabular}

\section{Quadro 2 - Grupos de aportes teóricos utilizados na CCT}

\section{Grupo teórico}

Representações do "eu"

Sistemas de produção cultural

Distinções e estruturas sociais

Comunidades de consumo

Ideologias e discursos de mercado

\section{Descrição}

Abordagens teóricas que dão suporte ao entendimento da expressão de subjetividades e construção de identidades por meio de práticas de consumo. Exemplos incluem teorias do self (e.g, transformação do "eu", "eu" estendido, posse) e identidade (e.g, reconstrução da identidade pessoal, identidade social, identidades culturais).

Esta dimensão teórica considera o poder da globalização cultural e econômica na transformação de ideais culturais em realidades materiais. Abordagens deste grupo incluem: mercantilização da cultura, comunicação de massa, sistema de publicidade, mitologização do consumo, experiência extraordinária, consumo em ambientes espetaculares, entre outras.

Diz respeito às forças estruturais que atuam sobre as atividades de consumo e sua repercussão na sociedade e nos indivíduos. Neste grupo, ganham relevo abordagens como: consumo conspícuo, manutenção de fronteiras e estruturas hierárquicas, gift-giving, consumo sagrado versus profano, capital cultural.

Considera comunidades formadas em torno da prática de consumo, com ênfase nas comunidades de marca e de estilos de vida específicos, sobretudo aqueles que se opõem aos padrões ditados pelas práticas sociais vigentes. É tratado em abordagens sobre ethos compartilhado, sentimento de pertença, cosmopolitismo, ritos de passagem, subculturas, neotribalismo, entre outras.

Esta abordagem encara o mercado como uma ideologia do sistema de produção e mediador das relações sociais em suas variadas esferas, bem como um lócus de resistência de minorias. Agência do consumidor, emancipação do consumidor, consumo global, feminismo, etnicidade, estudos culturais, ideologias de consumo, são exemplos de abordagens deste grupo. 
Se observado com base nos temas da CCT, "culturas de mercado" utiliza um grupo teórico de maneira exclusiva e outro com menor ênfase. O tema "projetos de identidade do consumidor" também utiliza um grupo teórico de maneira exclusiva, mas outros dois com menor ênfase. "Padrões sócio-históricos de consumo", por sua vez, também faz uso de três grupos teóricos, sendo um de modo dominante. Por fim, "ideologias de mercado massivamente mediadas e estratégias interpretativas dos consumidores" faz uso de dois grupos teóricos, que estão fundamentalmente ali concentrados, sugerindo que o termo aditivo na definição do campo temático revele dois grandes grupos de interesse, podendo-se sugerir a existência de dois "subgrupos": "ideologias de mercado massivamente mediadas" e "estratégias interpretativas dos consumidores".

Em relação à consistência das abordagens teóricas utilizadas com a proposta do campo de pesquisa da CCT, buscou-se identificar os artigos que se utilizaram de teorias não alinhadas à perspectiva em pauta. Dos 80 artigos constituintes do corpus de pesquisa, 13 foram classificados nesse critério. Em 12 deles, o que fica evi- denciado é a adoção de um construto cognitivista como cerne da pesquisa. A maioria deles, já consagrados pelo campo do comportamento do consumidor: escolha, satisfação, formação de preferência, risco percebido, envolvimento, comprometimento com marca, efeito de variáveis de gênero, padrões de preferência, processo decisório. Além destes, identificou-se, ainda: ansiedade, respostas emocionais e imaginação corporificada. Em outra direção, um dos artigos propõe-se à elaboração de uma teoria geral do consumo compulsivo, por meio de teorias de diferentes áreas. No entanto, focam-se, primordialmente, aspectos relacionados à personalidade, também demonstrando alinhamento ao campo de comportamento do consumidor.

Essas abordagens fazem parte de três dos cinco grupos teóricos identificados: representações do "eu", distinções e estruturas sociais e sistemas de produção cultural. Estes, por sua vez, alinham-se aos campos "padrões sócio-históricos de consumo", "projetos de identidade do consumidor" e o "subcampo", sugerido por este trabalho, "estratégias interpretativas dos consumidores”. Na seção anterior, já se discutiu uma possível

\section{Figura 2 - Grupos de aportes teóricos em relação aos campos temáticos da CCT}

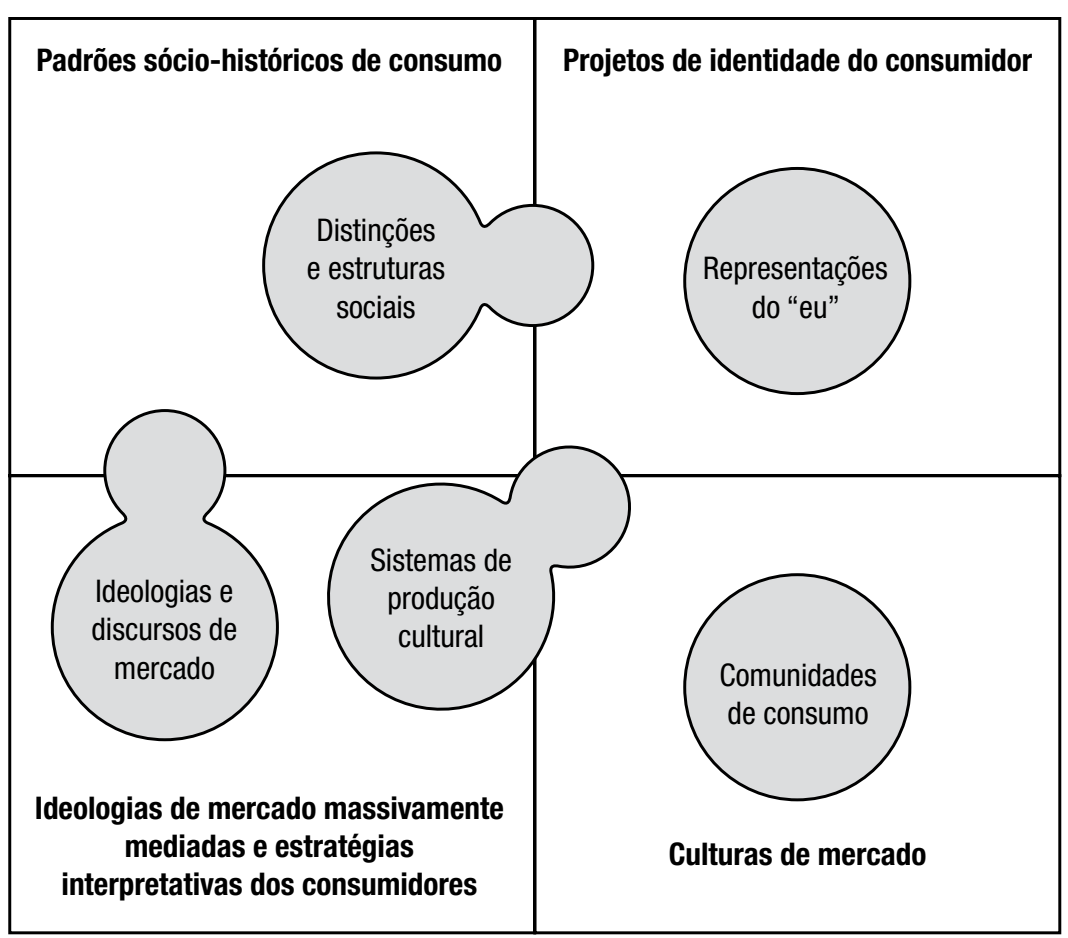


herança dos dois primeiros em relação ao comportamento do consumidor, argumento válido também para o terceiro - e que não valeria para "culturas de mercado" e "ideologias de mercado massivamente mediadas".

\section{Métodos adotados}

Os autores empregaram um variado arsenal de métodos para investigar os temas pertinentes à CCT. A seguir, serão apresentados os dados referentes à natureza de cada artigo (quantitativo, qualitativo, ensaio teórico) e ao volume de adoção de cada uma das estratégias de pesquisa identificadas (survey, etnografias, fenomenologia etc.).

No primeiro nível de análise, os artigos foram classificados de acordo com sua natureza, como exposto na Tabela 4. Os estudos qualitativos destacaram-se como a modalidade mais utilizada. A predominância de estudos de cunho qualitativo reforça as considerações feitas por Arnould e Thompson (2005) a respeito da abordagem dominante dos estudos da CCT. Segundo eles, apesar de não haver nenhum tipo de restrição quanto aos métodos de pesquisa, os trabalhos vinculados à CCT são, em sua maioria, qualitativos.
No segundo nível de análise, referente às estratégias de pesquisa empregadas pelos autores dos artigos analisados, os artigos foram classificados de acordo com as diferentes estratégias de pesquisa. Nesse ponto, em especial, o número total de artigos considerados foi reduzido a 74, uma vez que seis trabalhos do corpus inicial foram classificados como ensaios teóricos, não adotando procedimentos metodológicos (vide Tabela 5).

A etnografia, em suas várias modalidades, mostrou-se como o método mais utilizado, seguido pela fenomenologia. A terceira estratégia mais utilizada foi a survey. Vale destacar, todavia, que cinco dos sete artigos em que essa técnica é utilizada não se caracterizam como estudos quantitativos. Em três deles, a survey faz-se presente juntamente com abordagens qualitativas (correspondentes aos estudos de método misto apontados na Tabela 4) e, em outros dois, trata-se de questionários de perguntas abertas, também utilizados em conjunto com abordagens puramente qualitativas (estudos classificados como apenas qualitativos). Por fim, as estratégias de estudo de caso, grounded theory, estudos narrativos e experimento fizeram-se presentes em um número menor de artigos. Vale destacar que, a despeito do quantitativo, o que ora chamamos de estu-

\section{Tabela 4 - Estudos qualitativos, quantitativos e ensaios teóricos}

\begin{tabular}{|l|c|c|}
\hline \multicolumn{1}{|c|}{ Tipo de estudo } & No de artigos em que é adotado $^{\text {Q }}$ \% de artigos em que é adotado \\
\hline Qualitativo & 69 & 86,25 \\
\hline Quantitativo & 3 & 3,75 \\
\hline Misto & 2 & 2,50 \\
\hline Ensaio teórico & 6 & 7,50
\end{tabular}

\section{Tabela 5 - Estratégia de pesquisa nos artigos analisados}

Tipo de estudo

$\mathrm{N}^{0}$ de artigos em que é adotado

Estudos etnográficos

Fenomenologia

Survey

Estudo de caso

Grounded theory

Estudos narrativos

Experimento

Estudo qualitativo básico
30

13

7

4

2

1

1

17
$\%$ de artigos em que é adotado 40,54

17,56

9,45

5,40

2,70

1,35

1,35

23,00 
do qualitativo básico (vide MERRIAM, 1998) refere-se a artigos desenvolvidos como estudos qualitativos desvinculados de uma estratégia de pesquisa em específico.

Tudo leva a crer que a prevalência dos estudos etnográficos ocorra em virtude da natureza dos problemas abordados nos artigos, que, em sua maioria, procuram compreender o fenômeno do consumo assumindo a perspectiva do consumidor em seu ambiente cultural.

A presença de survey e experimento, por outro lado, parece sugerir o resquício, ainda que minoritário, de uma visão de ciência típica do campo de comportamento do consumidor. Não por representarem um problema em si quanto à aderência ao campo de CCT, uma vez que tal perspectiva defende a pluralidade metodológica. O que se identifica nesses trabalhos é a adoção de uma lógica hipotético-dedutiva de ciência, esta, sim, consonante ao positivismo, paradigma que se demonstra desalinhado a esta abordagem.

\section{Contribuições}

No que compete às contribuições dadas pela CCT para o entendimento das atividades de marketing, a análise do corpus de pesquisa demonstrou que cada um dos artigos apresentava, em seu objetivo, a intenção de responder ao menos a uma das perguntas "quê", "como", "quem", "por quê", "quando" e "onde" (Tabela 6).
Quanto à presença de cada uma das perguntas especificamente, a análise mostrou que todas elas foram abordadas por mais de um dos artigos que formavam o corpus, entretanto é notória a predominância da pergunta "como", acompanhada, em seguida, da pergunta "quê".

Entre os trabalhos analisados, a maioria buscou responder a apenas uma pergunta. Alguns artigos propuseram-se a responder a duas ou até três perguntas. Nenhum dos artigos apresentou em seu objetivo a intenção de responder a quatro ou mais das perguntas em questão (Tabela 7).

No que diz respeito ao padrão combinatório de perguntas naqueles artigos dedicados a responder a duas questões, "como" esteve presente em quase $80 \%$ das combinações, assim como "quê", "por quê", "como" e "onde" (em oito, cinco, quatro e um artigos, respectivamente). Importante destacar a articulação entre "como" e "quê", ratificando ainda mais a relevância dessas perguntas entre os trabalhos avaliados. A prevalência dessas duas perguntas, além de reforçar a predileção por um caráter descritivo das pesquisas vinculadas à CCT, teve na combinação de "que fenômeno" e "como o mesmo se dá" o caminho mais adotado pelos pesquisadores de modo a privilegiar o entendimento e a compreensão dos fenômenos, tratando de suas particularidades de acordo com os contextos em

\section{Tabela 6 - Perguntas de pesquisa tratadas nos artigos selecionados}

\begin{tabular}{|c|c|c|}
\hline Perguntas & $\mathbf{N}^{0}$ de artigos dedicados à pergunta & \% de artigos dedicados à pergunta \\
\hline Como & 55 & 68,75 \\
\hline Quê & 31 & 38,75 \\
\hline Por quê & 19 & 23,75 \\
\hline Quem & 5 & 6,25 \\
\hline Onde & 4 & 5,00 \\
\hline Quando & 3 & 3,75 \\
\hline
\end{tabular}

\section{Tabela 7 - Quantidade de perguntas tratadas por artigo}

\begin{tabular}{|c|c|c|}
\hline $\mathbf{N}^{0}$ perguntas abordadas/artigo & $\mathbf{N}^{0}$ de artigos & \% de artigos \\
\hline 1 & 53 & 66,25 \\
\hline 2 & 23 & 28,75 \\
\hline 3 & 6 & 7,50 \\
\hline 4 ou mais & 0 & 0,00 \\
\hline
\end{tabular}


que estão inseridos. Por fim, nos artigos que contemplam três questões, vale citar a presença do "como" em todos os casos, combinado de maneiras variadas com as demais indagações.

A ênfase no uso das perguntas "como" e "quê" provavelmente se deve à natureza interpretativista das pesquisas tratadas nesses artigos. De acordo com Creswell (2007), tal modalidade de pesquisa tenta desenvolver uma compreensão complexa e detalhada do problema estudado, o que exige a consideração de múltiplas perspectivas e a identificação dos muitos fatores que contribuem para retratar esse fenômeno. As respostas que emergem dessas questões atendem mais adequadamente às necessidades da investigação naturalista, visto que, segundo o mesmo autor, os pesquisadores não estariam obrigados à rigidez das ligações causa-efeito entre os fatores, mas, sim, à identificação das complexas interações desses fatores num determinado contexto. Talvez por isso a pergunta "por quê" apareça com menor intensidade nos artigos analisados, uma vez que, tipicamente, ela é utilizada com a finalidade de indicar a investigação de correlações ou causalidade entre variáveis. Finalmente, as perguntas "quem", "onde" e "quando" aparecem de maneira extremamente discreta. Uma inferência possível é de que sejam mais direcionadas a problemas gerenciais de marketing, o que, como se pode observar, não se trata de uma prioridade do campo da CCT.

\section{CONSIDERAÇÕES FINAIS}

Debruçando-se sobre um sentido diferente daquele relativo ao critério adotado para a análise realizada neste trabalho, pode-se assumir que, para promover efetiva contribuição a um campo de conhecimento, mais do responder a certo tipo de questionamento, os estudos devem fazer isso em consonância à agenda de pesquisa desse campo, bem como aos seus princípios norteadores. Nesse sentido, apesar de não se ter identificado nenhum artigo que não tenha respondido, por meio de seus resultados, à questão proposta, há que se refletir sobre a maneira como o fizeram em relação a aspectos teóricos e metodológicos basilares da CCT.

De um total de 80 artigos analisados, 14 merecem escrutínio a esse respeito. Entre os 13 artigos identificados como tendo utilizado abordagens teóricas cognitivistas, 8 o fizeram por meio de pesquisa quali- tativa com caráter interpretativista. Quatro deles usam a questão "como", um "quê" e outro "por quê", sendo essas últimas utilizadas conjuntamente nos outros dois. A inferência possível é de que haja, nesses trabalhos, uma apropriação, por assim dizer, do conhecimento estabelecido no campo do comportamento do consumidor, mas não uma descaracterização propriamente dita com a CCT.

Desse mesmo grupo, fazem parte os dois artigos que utilizam uma abordagem metodológica mista, ambos com questões "por quê". Todavia, enquanto um incorpora dados quantitativos e qualitativos num estudo de campo amplo, outro realiza análise quantitativa de todos os dados, incluindo os qualitativos. Enquanto o primeiro parece enquadrar-se na mesma situação dos artigos puramente qualitativos anteriormente mencionados, o segundo está claramente desalinhado ao modus operandi da CCT.

Ainda nesse grupo, encontram-se os três estudos quantitativos já comentados. Antes de a adoção de métodos quantitativos ser um problema propriamente dito no que concerne aos fundamentos da CCT, as premissas que esses três trabalhos carregam é que o são. Trata-se de estudos desenvolvidos sob a égide de aspectos ontológicos, epistemológicos e axiológicos alinhados a uma visão positivista de ciência, distantes, pois, das premissas interpretativistas que norteiam $\mathrm{o}$ campo de pesquisa. Curiosamente, os três têm suas questões de pesquisa elaboradas com base no "como". Logo, deduz-se que a problematização demonstra-se aderente à CCT, mas as escolhas feitas para a realização da pesquisa, não.

Por fim, existe um artigo que, apesar de ter utilizado uma abordagem teórica alinhada à CCT, ter definido uma questão típica da área ("como") e ter sido realizado por meio de pesquisa qualitativa (levantamento documental seguido de análise de conteúdo), foi problematizado de modo não consonante com esse campo, uma vez que se baseou em elaboração hipotética e teve sua análise convertida em frequência quantitativa. Com isso, pode-se concluir que ele não esteja alinhado aos princípios fundamentais da CCT.

Assim, pode-se dizer que, entre os 80 artigos analisados, apenas 14 não podem ser considerados totalmente integrados ao quadro referencial "puro" do que seriam os ditames da CCT, dos quais 9 podem ser incluídos como pertencentes à área, ainda que revelem resquícios do campo de comportamento do consumidor. Por outro lado, apenas 5 artigos podem ser entendidos como realmente desalinhados ao campo da 
CCT. Apesar disso, todos eles demonstram aspectos que os aproximam, de alguma maneira, a esta abordagem.

Dessa forma, ao término da análise do corpus de pesquisa, é possível afirmar que a CCT atende aos critérios determinados por este trabalho e referidos por Shaw, Jones e McLean (2010), podendo ser considerada uma escola de pensamento independente dentro do campo de estudo da pesquisa do consumidor. Esses artigos, antes de negarem essa inferência, parecem confirmá-la. Por um lado, os trabalhos que ainda flertam com a perspectiva dominante no campo de pesquisa do consumidor ressaltam o estatuto ainda infante dessa nova escola. Por outro, trabalhos realizados nos princípios desse modo dominante, que parecem travestir-se de CCT, só corroboram que essa abordagem tenha se consolidado.

A CCT é desenvolvida por vários pesquisadores e estudiosos, incluindo autores de renome na área, e conquistou seu espaço em diversos journals do universo acadêmico, possuindo, inclusive, journals dedicados exclusivamente aos seus trabalhos. Além disso, é constituída por um corpo sólido de conhecimento, com temáticas e teorias características, e que se preocupa em responder aos aspectos que norteiam as atividades de marketing. Por fim, é, ainda, marcada por uma abordagem primordialmente interpretativista, com predileção dos seus autores por métodos qualitativos de pesquisa.

Tendo como referência o recente trabalho de Palmer, Lindgreen e Vanhamme (2005), que apresentou o mesmo propósito que este em relação a outras escolas de pensamento no campo de marketing de relacionamento, o presente estudo aproxima-se daquele, ao utilizar como critério uma revisão crítica da produção de uma área, ao mesmo tempo em que se demonstra ainda mais específico do que aquele, ao adotar critérios objetivos e embasados na literatura.

É necessário destacar o fato de que o artigo de Arnould e Thompson (2005) baseou-se, em sua maior parte, em artigos publicados no Journal of Consumer Research, o que pode ser considerado uma limitação do trabalho realizado por eles e, consequentemente, estendida a este. Moisander, Peñaloza e Valtonen (2009) chamam a atenção para a importância da ampliação da perspectiva de Arnould e Thompson, valorizando, em especial, a produção europeia na área. Realmente, não se pode deixar de considerar os trabalhos de origem europeia, ainda mais pelo fato de os trabalhos de autores como Michel Foucault, Pierre Bourdieu, Jean Baudrillard, Mary Douglas e Karl Marx, todos europeus, terem influenciado fortemente as bases fundadoras da
CCT. No entanto, o que poderia parecer um argumento enfraquecedor em relação à consolidação da CCT como uma escola de pensamento vem corroborar a afirmação de que a CCT não se restringe apenas a um pequeno grupo de pesquisadores, mas, sim, é formada por estudiosos espalhados por diversas partes do globo, que vêm ganhando cada vez mais espaço e respeito no meio acadêmico.

Pode-se vislumbrar um campo fértil de possibilidades de novas pesquisas acerca da CCT como escola de pensamento. Revisões críticas mais específicas acerca da consistência entre as teorias adotadas, bem como da apropriação destas, uma vez que resultam, em sua maior parte, de outras áreas, parecem ser fundamentais. O mesmo vale para os procedimentos metodológicos. Apesar de a diversidade de abordagens ser uma das riquezas da pesquisa qualitativa, uma análise das questões relacionadas à consistência ontológica e epistemológica que as sustentam seria de grande criticidade.

\section{REFERÊNCIAS}

ACADEMY OF MARKETING SCIENCE. A ranking of marketing journals. Disponível em: http://www.ams-web. org/displaycommon.cfm?an=1\&subarticlenbr=10. Acesso em 08.12.2010.

ARNOULD, E. J; THOMPSON, C. J. Consumer culture theory (and we really mean theoretics): dilemmas and opportunities posed by an academic branding strategy. In: BELK, R. W; SHERRY, J. F. Consumer culture theory. Oxford: Elsevier, 2007.

ARNOULD, E. J; THOMPSON, C. J. Consumer culture theory (CCT): twenty years of research. Journal of Consumer Research, v. 31, n. 4, p. 868-882, 2005.

BAUDRILLARD, J. A sociedade de consumo. Lisboa: Edições 70, 2007.

BAUER, M. W; AARTS, B. A construção do corpus: um princípio para a coleta dedados qualitativos. In: BAUER, M. W; GASKELL, G. Pesquisa qualitativa em texto, imagem e som: um manual prático. Petrópolis: Vozes, 2005, p. 39-63.

BELK, R. W. Possessions and the extended self. Journal of Consumer Research, v. 15, n. 2, p. 139-168, 1988. 
BELK, R. W. What should ACR want to be when it grows up? In: LUTZ, R. J. (Ed.) Advances in Consumer Research, v. 13. Provo: Association for Marketing Research, 1986, p. 423-424.

BOOTH, W. C; COlOMB, G. G; Williams, J. M. A arte da pesquisa. São Paulo: Martins Fontes, 2008.

BOTTERILL, J. Cowboys, outlaws and artists: the rethoric of authenticity and contemporary jeans and sneaker advertisements. Journal of Consumer Culture, v. 7, n. 1, p. 105-125, 2007.

COVA, B; PACE, S; PARK, D. J. Global brand communities across borders: the Warhammer case. International Marketing Review, v. 24, n. 3, p. 313-329, 2007.

CRESWELL, J. W. Qualitative inquiry \& research research design: choosing among five approaches. 2. ed. Thousand Oaks: Sage Publications, 2007.

CROCKETT, D. Marketing blackness: how advertises use race to sell products. Journal of Consumer Culture, v. 8, n. 2, p. 245-268, 2008.

DOUGLAS, M; ISHERWOOD, B. O mundo dos bens: para uma antropologia do consumo. Rio de Janeiro: UFRJ, 2009.

DOLAN, P. Developing consumer subjectivity in Ireland: 1900-80. Journal of Consumer Culture, v. 9, n. 1, p. 117141, 2009.

DWYER, R. E. Making a habit of it: positional consumption, conventional action and the standard of living. Journal of Consumer Culture, v. 9, n. 3, p. 328-347, 2009.

FEATHERSTONE, M. Cultura de consumo e pós-modernidade. São Paulo: Nobel, 1995.

HAMLETT, J. Ethnicity and consumption: south asian food shopping patterns in Britain. Journal of Consumer Culture, v. 8, n. 1, p. 91-116, 2008.

HEARN, A. Meat, mask, burden: probing the contours of the branded self. Journal of Consumer Culture, v. 8, n. 2, p. 197-217, 2008.

HIRSCHMAN, E. C; THOMPSON, C. J. Why media matter: towards a richer underslanding of consumers' relationships with advertising and mass media. Journal of Advertising, v. 26, n. 1, p. 43-60, 1997.
HOLBROOK, M. B. Nostalgia and consumption preferences: some emerging patterns of consumer tastes. Journal of Consumer Research, v. 20, n. 2, p. 245-256, 1993.

HOLBROOK, M. B; O'SHAUGHNESSY, J. On the scientific status of consumer research and the need for an interpretive approach to studying consumption behavior. Journal of Consumer Research, v. 15, n. 3, p. 398-402, 1988.

HOLIDAY, R; CAIRNIE, A. Man made plastic: investigating men's consumption of aesthetic surgery. Journal of Consumer Culture, v. 7, n. 1, p. 57-78, 2007.

HOLT, D. B. Poststructuralist lifestyle analysis: conceptualizing the social patterning of consumption. Journal of Consumer Research, v. 23, n. 4, p. 326-350, 1997.

KASSARJIAN, H; GOODSTEIN, R. C. The emergence of consumer research. In: MACLARAN, P. e outros (Eds). The Sage handbook of marketing theory. London: Sage Publications, 2010.

MERRIAM, S. B. Qualitative research and case study applications in education: revised and expanded from case study research in education. San Francisco: Jossey-Bass, 1998.

MOISANDER, J; PEÑAlOZA, L; VALTONEN, A. From CCT to CCC: building consumer culture community. In: SHERRY, J. F; FISCHER, E. (Eds). Explorations in consumer culture theory. New York: Routledge, 2009.

MUNIZ, A; O'GUINN, T. C. Brand Communities. Journal of Consumer Research, v. 27, n. 4, p. 412-432, 2001.

OUWERSLOOT, H; ODEKERKEN-SCHRÖDER, G. Who's who in brand communities - and why? European Journal of Marketing, v. 42, n. 5, p. 571-585, 2008.

PALMER, R; LINDGREEN, A; VANHAMME, J. Relationshiop marketing: schools of thought and future research directions. Marketing Intelligence \& Planning, v. 23, n. 3, p. 313-330, 2005.

PEÑALOZA, L; GILLY, M. Marketer acculturation: the changer and the changed. Journal of Marketing, v. 63, n. 3, p. 84-104, 1999.

PIETRANGELO, M. Tipos de pesquisa. In: MALHOTRA, N. K. Pesquisa de marketing: uma orientação aplicada. 4. ed. Porto Alegre: Bookman, 2006. 
PINTO, M. R; LARA, J. E. Desvendando as experiências de consumo da perspectiva da teoria da cultura do consumo: possíveis interlocuções e questões emergentes para a pesquisa do consumidor. In: Encontro Nacional da Associação Nacional dos Programas de Pós-graduação em Administração, 33, 2009, São Paulo. Anais. São Paulo: ANPAD, 2009.

SCHOUTEN, J; MCALEXANDER, J. H. Subcultures of consumption: an ethnography of the new bikers. Journal of Consumer Research, v. 22, n. 1, p. 43-61, 1995.

SHAW, E. H; JONES, D. G. B; MCLEAN, P. A. The early schools of marketing thought. In: MACLARAN, P. e outros (Eds). The Sage handbook of marketing theory. London: Sage Publications, 2010.

SHETH, J. N; GARDNER, D. M; GARRET, D. Marketing theory: evolution and evaluation. New York: Wiley and Sons, 1988.

SHETH, J. N.; PARVATIYAR, A. The evolution of relationship marketing. International Business Review, v. 4, n. 4, p. 397-418, 1995.

SLATER, D. Cultura do consumo e modernidade. São Paulo: Nobel, 2002.

TADAJEWSKI, M. Remembering motivation research: toward an alternative genealogy of interpretive consumer research. Marketing Theory, v. 6, n. 4, p. 429-466, 2006.

THERKELSEN, A; GRAM, M. The meaning of holiday consumption. Journal of Consumer Culture, v. 8, n. 2, p. 269292, 2008.

TRENTMANN, F. Crossing divides: consumption and globalization in history. Journal of Consumer Culture, v. 9, n. 2, p. 187-220, 2009.

WISSINGER, E. Modeling consumption: fashion modeling work in contemporary society. Journal of Consumer Culture, v. 9, n. 2, p. 273-296, 2009. 